\title{
$\mathrm{AHP}$ 기법을 적용한 산업재해예방사업 심층평가 항목의 가중치 설정 이 준 희 $\cdot$ 정 필 균 ${ }^{*}$ 이 정 배*** 노 재 훈 ${ }^{* *} \cdot$ 원 종 욱** \\ "연세대학교 보건대학원 및 의과대학 산업보건연구소
}

**연세대학교 의과대학 예방의학교실 및 산업보건연구소. ${ }^{* * *}$ 단국대학교병원 직업환경의학과

\section{Evaluations of Industrial Accident Prevention Program of Korea by using Analytic Hierarchy Process(AHP) method}

\author{
June-Hee Lee $^{*} \cdot$ Pilkyun Jung ${ }^{*} \cdot$ Jeongbae Rhie ${ }^{* * *} \cdot$ Jaehoon Roh $^{* *} \cdot$ Jong-Uk Won $^{* *}$ \\ ${ }^{*}$ Graduate School of Public Health, Yonsei University and Institute for Occupational Health, \\ Yonsei University College of Medicine \\ ${ }^{* *}$ Department of Preventive Medicine and Institute for Occupational Health, \\ Yonsei University College of Medicine \\ ${ }^{* * *}$ Department of Occupational and Environmental Medicine, \\ Dankook University Medical Center
}

\begin{abstract}
We undertook the quantitative evaluations of Industrial Accident Prevention Program (IAPP). The six parameters, such as relevance, efficiency, consistency, sustainability, effectiveness, coherence, were chosen by expert plenary sessions. Two stage of Analytic Hierarchy Process were used to determine the weighted value of assessment criteria. This expert plenary suggests that the six parameters and its weight values are useful for quantitative evaluations of IAPP. Additional researches regarding the real world application of this assessment tool should be initiated.
\end{abstract}

Key words : AHP, Industrial Accident Prevention Program

1. 서 론

현재 고용노동부 및 안전보건공단이 수행하고 있는 산재예방사업에 대해 평가가 이루어지고 있지만 경영 전반에 대한 정성적 평가에 치우치고, 종전의 산재예방 사업별 평가가 개별사업 단위별 효과분석에 머무는 등 한계성을 노출하고 있다. 이에 따라 한정된 국가자원의 효율적인 집행을 위하여 현재 수행되는 산재예방산업
에 대해 적절성, 타당성, 효과성, 경제성, 사업성과 등 을 고려한 전반적이고 객관적인 평가가 필요하며 이에 산재예방사업 심층평가의 필요성이 대두 되었다.

이에 따라 산재예방사업의 심층평가를 위하여 평가 관점, 평가지표, 평가요소 등을 도출하고, 실제 심층평 가를 위한 세부 평가방법, 평가도구, 상호비교 방법 등 을 개발 하고자 하며 평가 하는 항목별 가중치 설정을 위하여 $\mathrm{AHP}$ 기법을 사용하여 연구를 진행 하고자 한다.

† Corresponding Author: Jong-Uk Won, Department of Preventive Medicine and Institute for Occupational Health, Yonsei University College of Medicine. 450, Shinchon-dong, Seodaemun-gu, Seoul, M P P : 010-4722-5343, E-mail : JUWON@yuhs.ac

Received October 20, 2013; Revision Received December 2, 2013; Accepted December 2, 2013. 


\section{2. 이론적 배경}

\section{1 산재예방사업평가의 이해}

Winslow (1920)는 공중보건을 사회의 조직적 노력을 통 하여 질병을 예방하고, 수명을 연장하며 건강을 증진시키 는 과학이며 예술이라고 정의하였는데, 예방과 집단차원의 건강문제에 초점을 두고 있다. 산재예방사업의 궁극적인 목적은 질병, 상해, 불구 및 사망의 예방과 관리에 있다. 이러한 목적을 달성하기 위한 사업은 시대적 상황이 복잡 해져 가고 있는 것만큼 복잡해져 가고 있는 실정이대[1].

산재예방사업 자체의 특성이 다양해지고 규모가 큰 문제들을 다루면서, 대규모의 지역사회 구성원과 기관 들이 함께 참여하여 문제해결점을 모색해야 하는 상황 으로 바뀌고 있다. 즉, 예전의 예방접종이나 위생체계 의 변화를 통해 문제를 해결했던 수준이나 전염병 예 방 및 환경적 위해에 관한 단편적인 대상자 교육을 수 행했던 것 같이 단순한 차원의 보건문제들을 넘어서, 이제는 소비자와 공급자의 지식, 태도 및 행동에 변화 를 일으키고, 전 세계적으로 유익을 가져오는 차원까지 확대되어 그 복잡성이 증가되었다(US DHHS, 2005)[2].

또한 이미 성공한 산재예방사업 이라고 하여도 다른 지역이나 상황에서는 같은 결과를 도출하지 못하는 경 우가 발생하여 개발된 보건사업의 보급에도 많은 제한 점이 있을 수 있다. 산재예방사업은 근로자의 건강을 보호하고 강화하는 데에 있어서 필수적이며, 이는 공공 차원에서 지원이 되었기 때문에, 이 사업들이 평가되어 야 하는 것은 당연한 일이며, 보건사업 및 분야의 다양 성만큼 평가의 접근도 달라져야 할 것이다.

\section{2 프로그램 평가의 정의 및 기준}

\subsection{1 프로그램 평가의 정의}

이전에는 평가를 종종 프로젝트 사이클의 마지막 단 계라 보고, 모든 프로그램 활동이 끝나고 난 후에 행해 지는 것이라고 여겼으며, 아직도 많은 분야에서 그러한 개념을 벗어나지 못한 것이 현 실정이다. 따라서 프로 그램 평가에 대한 정의와 그 목적을 분명히 이해하는 것이 우선 되어야하며, 프로그램 평가는 프로그램 수행 및 결과에 대한 질문에 답변하는 객관적이고 체계적인 연구이다(GAO, 2000)[3].

Rossi et al. (1999)에 의하면, 프로그램 평가란 사회 연구절차를 사용하여 체계적으로 해당 프로그램의 효과 성을 조사하는 것이라고 정의하였으며[4], Chen(2005)은 체계적으로 해당 프로그램을 사정하여 계획, 수행 및 효과를 증진하기 위하여 평가의 접근, 기술과 지식을 적용하는 것이라고 정의했다[5].

\subsubsection{European Commission(2005)}

$<$ Table 2> European Commission(2005)

\begin{tabular}{|c|c|}
\hline 평가이슈 & 정의 \\
\hline $\begin{array}{l}\text { 적절성 } \\
\text { relevance }\end{array}$ & $\begin{array}{c}\text { 중재의 목적이 요구문제나 시사된 } \\
\text { 이슈에 적절한 정도 }\end{array}$ \\
\hline $\begin{array}{c}\text { 일치성 } \\
\text { Coherence }\end{array}$ & $\begin{array}{c}\text { 사업로직이 모순되지 않거나 } \\
\text { 사업이 유사한 목적을 가진 다른 } \\
\text { 사업들과 모순되지 않는 정도 }\end{array}$ \\
\hline $\begin{array}{l}\text { 경제성 } \\
\text { Economy }\end{array}$ & $\begin{array}{c}\text { 자원이 필요한 때에, 가장 좋은 } \\
\text { 가격으로 적절한 양과 질로 이용될 } \\
\text { 수 있는 정도 }\end{array}$ \\
\hline $\begin{array}{c}\text { 효과성 } \\
\text { effectiveness }\end{array}$ & 설정한 목적이 성취되는 정도 \\
\hline $\begin{array}{l}\text { 효율성 } \\
\text { efficiency }\end{array}$ & $\begin{array}{c}\text { 합리적인 비용으로 기대되는 } \\
\text { 효과가 성취되는 정도 }\end{array}$ \\
\hline $\begin{array}{c}\text { 지속성 } \\
\text { sustainability }\end{array}$ & $\begin{array}{c}\text { 긍정적인 효과가 중재가 종료된 } \\
\text { 후에도 지속되는 정도 }\end{array}$ \\
\hline $\begin{array}{l}\text { 유용성 } \\
\text { utility }\end{array}$ & $\begin{array}{c}\text { 효과가 요구문제와 제기된 이슈에 } \\
\text { 상응하는 정도 }\end{array}$ \\
\hline $\begin{array}{l}\text { 일관성 } \\
\text { consistency }\end{array}$ & $\begin{array}{c}\text { 다른 경제, 사회 또는 정책분야로 } \\
\text { 긍정적/부정적 일출효과가 } \\
\text { 최대화/최소화되는 정도 }\end{array}$ \\
\hline $\begin{array}{l}\text { 분배효과 } \\
\text { allocative } \\
\text { effects }\end{array}$ & $\begin{array}{c}\text { 정책의 불균형적 부정적/긍정적 } \\
\text { 분배효과가 최소화/최대화되는 } \\
\text { 정도 }\end{array}$ \\
\hline $\begin{array}{l}\text { 수용가능성 } \\
\text { acceptability }\end{array}$ & $\begin{array}{c}\text { Stakeholders가 일반적으로 정책 } \\
\text { 및 제안되거나 채택된 특수도구를 } \\
\text { 수용하는 정도 }\end{array}$ \\
\hline
\end{tabular}

European Commission (2005)은 평가의 초점이 무엇 보다도 보건사업에 대한 요구, 결과 및 효과여야 한다 고 하며, 조작적 정의로 평가는 주로 적절성, 효율성, 효과성, 지속가능성 등 같은 이슈를 조사하는 것으로 정의하였다[6].

사업 평가를 위해서는 평가 시 설문을 구체적으로 개발해야 하며 이 질문들을 통해 평가 이슈가 구체화, 범주화될 수 있다. 특정한 평가가 산출하는 정보의 양 은 개발된 평가질문의 수에 따라 결정되게 되며, 어느 단계에 평가를 하느냐에 따라 평가할 내용도 결정되므 로 평가이슈는 타이밍에 상당히 의존하게 된다고 볼 수 있다. 즉 평가의 주기에서 어느 단계에 있느냐에 따 라 관련된 또는 타당한 평가이슈를 선택해야 하며, 이 때 평가 이슈들로 사용되는 용어들은 그 개념정의를 분명히 해야 한다. 


\subsubsection{American Evaluation Association}

American Evaluation Association에서는 프로그램 평가 기준을 유용성, 실현가능성, 정확성, 책임성으로 나누어 그 기준을 제시하였다.

유용성(Utility)은 프로그램 수행자가 평가 과정과 그 들의 요구를 충족시키는 결과물을 찾는 정도를 증가시 키는 데에 목적을 둔다. 실현가능성(Feasibility)은 프로 그램의 효과성과 효율성을 증가시키기 위하는데 목적 을 둔다. 적절성(Propriety)은 평가에 있어 적절성, 공 평성, 입법성, 정당성을 지원한다. 정확성(Accuracy)은 특히 질에 관한 해석과 판단을 지원하는 평가 진술, 명 제, 결과의 신뢰성과 진실성을 증가시키는 데에 목적을 둔다. 책임성(Accountability)은 평가의 적절한 문서화 와 평가과정과 산출물에 대한 향상과 책임소재에 초점 을 둔 메타평가적인 관점을 지향한다[7]. 산재예방 사 업 프로그램을 평가하기 위해서는 먼저 각 프로그램의 특성을 고려한 평가의 기준과 범주를 설정하여 평가의 방향을 제시하는 것이 중요하다. 예를 들어, 유사한 분 야의 산재예방 사업 프로그램의 경우, 개발된 적정한 평가기준을 사용하는 것은 자체 프로그램의 개발, 수행, 평가 및 관리에 있어서 실질적이고 유용하게 활용되어 질 뿐 아니라, 프로그램 간의 비교평가를 가능하게 하 여 평가의 신뢰성을 높여 준다[8].

\section{3 평가의 종류 및 목적}

평가는 평가가 수행되는 시기에 따라 형성평가 (formative), 과정평가(process) 그리고 최종평가(summa tive evaluation) 로 나누어지는데, 이 평가의 유형에 따 라 그 목적의 차이가 있다. 형성평가(Formative evaluati on)는 프로그램의 개발 및 향상 중에 수행되는 것으로 종종 한 번 이상 수행되며, 그 목적은 프로그램을 향상 시키기 위하여 피드백을 주는 데에 있다. 과정 평가 (Process evaluation)는 프로그램이 실제 진행되는 가운 데 수행, 분석되는 것으로, 특별히 프로그램의 과정과 성과에 관한 중요한 영향을 파악하고 이해하는 데에 목 적을 둔다. 최종평가 (Summative evaluation)는 평가되 는 대상의 결과가 설정된 목적을 충족시켰는지 여부를 사정하는 것으로, 프로그램 향상을 이유 보다는 평가적 인 결론을 필요로 하는 관찰자나 의사결정자들을 위해 서 또는 그들에 의해서 이루어진다(Scriven, 1991)[9].

프로그램 평가의 수행을 위해서는 평가의 목적을 분 명히 수립해야 하며, 평가를 위한 평가영역을 확정해야 한다. 프로그램의 특성에 따라 그 목적도 다르고, 평가 내용도 달라지므로 획일적인 평가 틀을 개발하는 것은 어려운 일이지만 평가를 위한 표준화되거나 타당성이 입증된 기준(Norms and standards)을 정하는 것이 평 가에 도움이 된다(UNODC)[10].

\section{4 평가의 요소}

과거의 평가는 블랙박스모델(Black box model)을 적 용했다고 볼 수 있는데, 이는 투입 (inputs)에 대한 산 출(outputs)을 조사하는 수준으로, 어떠한 프로그램을 수행하였을 때 수행 직후 나타나는 결과를 중심으로 보고가 이루어졌다. 그러나 블랙박스모델(Black box model)은 프로그램이 어떻게 결과에 기여했는지에 대 한 정보를 알 수 없고, 따라서 앞으로의 프로그램 향상 을 위한 구체적인 방향을 제시해 줄 수 없게 한다. 따 라서 프로그램이 결과를 산출하는 과정에 대한 이해와 프로그램 수행으로 인한 직접적인 영향에 의한 결과뿐 만 아니라 간접적인 영향을 통해 나타나는 결과에 대 한 평가가 관심을 가지게 되었으며 이는 소위 중재와 결과 사이에 블랙박스(black box)를 여는 차원의 평가 로 등장하게 된다. Figure 2 는 사업수행 로직에 관한 요소와 개념을 소개하면서 동시에 앞서 언급한 평가의 기본적인 이슈를 측정할 수 있도록 도식적으로 그 정 의를 보여주는 좋은 예이다[11].

Figure 1 에서 보듯이 프로그램 수행 시 그 규모는 평가의 목적에 따라 달라질 수 있고, 앞서 언급한 바와 같이 프로그램 개발 중에 프로그램의 향상을 목적으로 수행하는 것인지, 수행 중에 수행정도와 그 과정을 평 가하고자 하는 것인지, 아니면 의사결정자들에게 최종 프로그램에 관한 결정을 내릴 수 있도록 정보를 제공 하고자 하는지에 따라 평가의 질문도, 기준도 달라질 것이며, 평가방법도 차이가 있어야 한다.

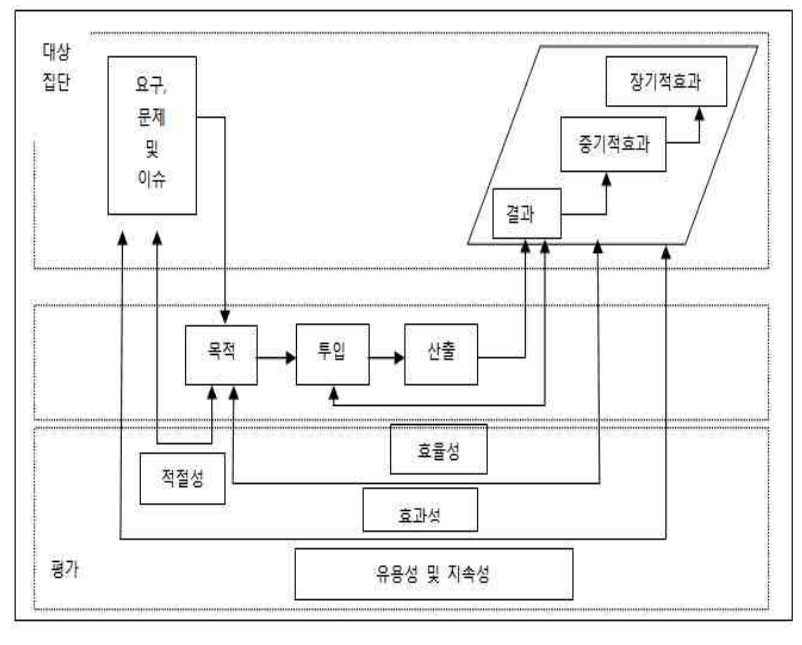

European Commission, 2005

[Figure 1] Business on the logic diagram (European Commission, 2005) 


\section{AHP 기법을 통한 평가지표별 가중치 설정}

\section{1 평가 항목 설정}

$<$ Table 2> Assessment and evaluation tools

\begin{tabular}{|c|c|c|c|c|c|c|}
\hline \multirow{2}{*}{ 평가단계 } & \multicolumn{5}{|c|}{ 평가의 관점 } \\
\cline { 2 - 7 } & 적절성 & 효과성 & 효율성 & 효용성 & 일관성 & 지속성 \\
\hline 계획단계 & $\circ$ & & & & & \\
\hline 집행단계 & & & $\circ$ & & $\circ$ & \\
\hline 성과단계 & & $\circ$ & & $\circ$ & & $\circ$ \\
\hline
\end{tabular}

위의 사업평가 기법들을 이용하여 산재예방사업의 특성을 반영한 평가 지표를 개발 하였고 내용은 다음 과 같다. 적절성(Relevance)은 사업의 목표(objectives) 가 사업의 수요(need)를 충족시키기 위해 얼마나 잘 설 정되어 있으며 정부정책과 얼마나 부합하고 있는가를 파악하는 항목 이며 효율성(efficiency)은 여러 투입 (input)이 얼마나 경제적으로 사용되어 산출(outputs) 및 중간결과(results)로 전환되었는가를 파악한다. 효과 성(effectiveness)은 사업의 결과(impacts)가 사업의 특 정목표 및 일반목표를 달성하는데 얼마나 기여했는지 를 파악한다. 이는 정책사업의 시행으로 달성될 수 있 는 효과를 말한다. 장단기 목표 달성도 파악하며 효용 성(utility)은 사업의 결과가 실제로 사업의 수요가 얼 마나 충족되었는가를 판단한다. 일관성(consistency)은 사업의 수행이 사업의 목표와 계획과 일치되게 집행되 는 정도를 통해 판단한다. 지속성(sustainability)은 사 업이 중단되었을 때 사업으로 인한 긍정적 변화가 얼 마나 오랫동안 지속될 수 있을 것인가와 사업 자체의 지속가능성을 판단한다.

\section{2 지표별 가중치 설정 방법}

평가 항목에 대한 가중치 설정은 위와 같은 과정을 거쳐 선정된 전문가 $9 \sim 12$ 인을 대상으로 2 단계 Analytic Hierarchy Process(AHP) 분석을 통하여 도출 하도록 하였다.

AHP 분석은 1970년대 초반에 Saaty가 개발한 방법 으로, 의사결정과정에서 상호관련성을 갖는 요소들을 계층화하고 이를 쌍대비교(Pairwise Comparison)하여 정량적인 값을 도출해 의사결정을 돕는 방법이다. $\mathrm{AHP}$ 설문을 위한 패널을 구성하여 패널의 주관적인 판단을 정량화하여 가중치를 도출하였다[12][13].
심층평가사업을 크게 네 가지 분야(안전, 보건, 위생, 건설)로 나눈 뒤 평가를 위한 관련자 및 전문가는 해당 분야의 실무 및 연구 경력이 10 년 이상인 인원을 대상으 로 사전에 구성을 완료한 뒤, 해당 인원에 대한 연구진들 간의 논의를 거쳐 선택 편견을 최소화 하도록 하였다.

이들 패널을 대상으로 사업단계 및 6 가지 평가지표 그리고 세부 평가 내용에 대한 2 단계 $\mathrm{AHP}$ 분석을 통 해 해당 지표별 가중치를 도출하였다.

1 차 $\mathrm{AHP}$ 설문이 종료 된 뒤 설문 대상자별로 도출 된 일관성지수(Consistency index, $\mathrm{CI}$ )와 일관성비율 (Consistency rate, $\mathrm{CR}$ )값을 산출하여 패널이 내린 판 단의 논리적 모순을 검정한 뒤, 모순이 발견 될 경우 해당 패널에게 $\mathrm{AHP}$ 설문 방법에 대한 추가적인 설명 을 덧붙여 2차 설문을 시행한다. 2차 설문을 통하여 얻 어진 결과를 토대로, 일관성비율 $(\mathrm{CR})$ 값이 부족한 응답 항목은 폐기하고, 일관성이 유지되는 응답지만을 토대 로 기하평균을 산출하였으며 얻어진 값으로 해당 분야 의 지표별 가중치를 구하고 최종적으로 이를 바탕으로 각 사업을 종합 평가하였다[14].

\section{3 결과 분석}

\subsection{1 보건분야}

보건 분야 $\mathrm{AHP}$ 설문에는 총 11 명의 전문가가 참여 하였다. 응답자의 해당 분야 평균 경력은 17.2 년으로 나타났고, 응답자 중 10 명이 현재 직업의 형태를 문는 질문에 대학 교수라고 응답해 대다수를 차지했다. 보건 사업 평가 항목 및 평가 지표에 따른 가중치는 사업의 단계 상 계획단계 $50 \%$, 성과단계 $35 \%$, 집행단계 $15 \%$ 로 나타나 계획단계에 가장 높은 가중치가 부여 되었 고, 이에 따라 여섯 가지 평가 항목에서도 사업의 적절 성에 $50 \%$ 로 가장 높은 가중치가 부여 되었다. 그 외 집행단계에 해당하는 사업의 효율성과 일관성 간에는 각 $7 \%$ 와 $8 \%$ 로 비슷한 정도의 가중치가 부여되었고, 성과 단계에 해당하는 효과성과 지속성은 약 $15 \%$ 정도 로 비슷한 가중치가, 효용성의 경우 $6 \%$ 로 상대적으로 낮은 가중치가 부여 되었다. 세부 평가 내용의 경우 사 업의 필요성이 $26 \%$ 로 가장 높은 가중치를 부여 받았 고, 성과목표 부합성 $(13 \%)$, 기획의 합리성 $(11 \%)$ 등이 그 뒤를 이었다. 그 외, 기타 분야의 사업의 경우에도 대부분이 홍보활동과 관련된 사업으로 보건사업과 마 찬가지로 즉각적인 성과를 기대하기 힘들다는 데에 있 어서 그 특징을 공유하므로 기타 분야의 사업의 경우 에도 보건사업과 동일한 가중치를 부여하였다(CI:0.069, CR: 0.070). 
$<$ Table 3> Health services, assessment items and weightings

\begin{tabular}{|c|c|}
\hline 단계 & 평가 항목 \\
\hline $\begin{array}{l}\text { 계획 } \\
(50 \%)\end{array}$ & 사업의 적절성 $(50 \%)$ \\
\hline \multirow{2}{*}{$\begin{array}{c}\text { 집행 } \\
(15 \%)\end{array}$} & 사업의 효율성 $(7 \%)$ \\
\hline & 일관성 $(8 \%)$ \\
\hline \multirow{3}{*}{$\begin{array}{l}\text { 성과 } \\
(35 \%)\end{array}$} & 효과성 (14\%) \\
\hline & 효용성 (6\%) \\
\hline & 지속성 $(15 \%)$ \\
\hline
\end{tabular}

\subsection{2 건설분야}

건설 분야 $\mathrm{AHP}$ 설문에는 총 12 명의 전문가가 참여 하였다. 응답자의 해당 분야 평균 경력은 20.8 년으로 나타났고, 응답자 중 11 명이 현재 직업의 형태를 묻는 질문에 실무 경력자로 응답해 대다수를 차지했다. 건설 사업 평가 항목 및 평가 지표에 따른 가중치는 사업의 단계 상 성과단계 $40 \%$, 집행단계 $30 \%$, 계획단계 $30 \%$ 로 나타나 성과단계에 가장 높은 가중치가 부여 되었 다. 여섯 가지 평가 항목의 경우 사업의 적절성에 $30 \%$ 로 가장 높은 가중치가 부여 되었으며, 그 외 집행단계 에 해당하는 항목의 경우 효율성이 $17 \%$ 로 상대적으로 높은 가중치를 부여받았고, 성과단계에 해당하는 항목 의 경우 효과성이 $21 \%$ 로 높은 가중치를 부여받았다. 세부 평가 내용의 경우 목표와 집행의 일관성이 $13 \%$ 로 가장 높은 가중치를 부여 받았고, 사업 만족도 $(11 \%)$, 성과목표 부합성 $(12 \%)$ 등이 그 뒤를 이었다(CI:0.006, CR: 0.011).

$<$ Table $4>$ Construction services, assessment items and weightings

\begin{tabular}{|c|c|}
\hline 단계 & 평가 항목 \\
\hline $\begin{array}{c}\text { 계획 } \\
(30 \%)\end{array}$ & ·사업의 적절성 $(30 \%)$ \\
\hline \multirow{2}{*}{$\begin{array}{c}\text { 집행 } \\
(30 \%)\end{array}$} & ·사업의 효율성 $(17 \%)$ \\
\cline { 2 - 2 } & · 일관성 $(13 \%)$ \\
\hline \multirow{2}{*}{$\begin{array}{c}\text { 성과 } \\
(40 \%)\end{array}$} & ·효과성 $(21 \%)$ \\
\cline { 2 - 3 } & ·효용성 $(11 \%)$ \\
\hline
\end{tabular}

\subsection{3 위생분야}

위생 분야 $\mathrm{AHP}$ 설문에는 총 9 명의 전문가가 참여하 였다. 응답자의 해당 분야 평균 경력은 18.4년으로 나타 났고, 응답자 중 5 명이 현재 직업의 형태를 묻는 질문 에 대학교수로 응답해 다수를 차지했다. 위생사업 평가 항목 및 평가 지표에 따른 가중치는 사업의 단계 상 성 과단계 $40 \%$, 계획단계 $35 \%$, 집행단계 $25 \%$ 로 나타나 성과단계에 가장 높은 가중치가 부여 되었다. 여섯 가 지 평가 항목의 경우 사업의 적절성에 $35 \%$ 로 가장 높 은 가중치가 부여 되었으며, 그 외 집행단계에 해당하 는 항목의 경우 일관성이 $15 \%$ 로 상대적으로 높은 가중 치를 부여받았고, 성과단계에 해당하는 항목의 경우 효 용성이 $16 \%$ 로 높은 가중치를 부여받았다. 세부 평가 내 용의 경우 사업의 필요성이 $17 \%$ 로 가장 높은 가중치를 부여 받았고, 사업 만족도 $(16 \%)$, 목표와 집행의 일관성 (15\%) 등이 그 뒤를 이었다(CI:0.070, CR: 0.025).

$<$ Table 5> Clean services, assessment items and weightings

\begin{tabular}{|c|c|}
\hline 단계 & 평가 항목 \\
\hline $\begin{array}{c}\text { 계획 } \\
(35 \%)\end{array}$ & · 사업의 적절성 $(35 \%)$ \\
\hline \multirow{2}{*}{$\begin{array}{c}\text { 집행 } \\
(25 \%)\end{array}$} & ·사업의 효율성 $(10 \%)$ \\
\cline { 2 - 2 } & · 일관성 $(15 \%)$ \\
\hline \multirow{2}{*}{$\begin{array}{c}\text { 성과 } \\
(40 \%)\end{array}$} & ·효과성 $(9 \%)$ \\
\cline { 2 - 2 } & ·효용성 $(16 \%)$ \\
\cline { 2 - 3 } & · 지속성 $(15 \%)$ \\
\hline
\end{tabular}

\subsection{4 안전분야}

안전 분야 $\mathrm{AHP}$ 설문에는 총 8 명의 전문가가 참여하 였다. 응답자의 해당 분야 평균 경력은 23.9 년으로 나 타났고, 응답자들은 현재 직업의 형태를 묻는 질문에 4 명이 대학교수라고 응답해 다수를 차지했다. 안전사업 평가 항목 및 평가 지표에 따른 가중치는 사업의 단계 상 성과단계 $60 \%$, 집행단계 $25 \%$, 계획단계 $15 \%$ 로 나 타나 성과단계에 가장 높은 가중치가 부여 되었다. 여 섯 가지 평가 항목의 경우 성과단계에 해당하는 효용 성에 $29 \%$ 로 가장 높은 가중치가 부여 되었으며, 그 외 지속성 $(23 \%)$, 사업의 효율성 $(18 \%)$ 등이 차례로 높은 가중치를 받았다. 세부 평가 내용의 경우 사업 만 족도가 $29 \%$ 로 가장 높은 가중치를 부여 받았고, 사업 효과의 지속성 (18\%), 사업의 효율적 진행 여부 (11\%) 등이 그 뒤를 이었다(CI:0.015, CR: 0.071). 
$<$ Table 6> Safety services, assessment items and weightings

\begin{tabular}{|c|c|}
\hline 단계 & 평가 항목 \\
\hline $\begin{array}{l}\text { 계획 } \\
(15 \%)\end{array}$ & - 사업의 적절성 $(15 \%)$ \\
\hline \multirow{2}{*}{$\begin{array}{c}\text { 집행 } \\
(25 \%)\end{array}$} & · 사업의 효율성 (18\%) \\
\hline & - 일관성 $(7 \%)$ \\
\hline \multirow{3}{*}{$\begin{array}{l}\text { 성과 } \\
(60 \%)\end{array}$} & · 효과성 (8\%) \\
\hline & · 효용성 (29.0\%) \\
\hline & - 지속성 $(23.0 \%)$ \\
\hline
\end{tabular}

\section{4. 결론 및 향후 연구 과제}

이전 시행되었던 고용보험사업 평가는 2007년부터 추진되면서 기획재정부의 기금운용 평가에 대응하는 기초자료 마련을 위한 평가로서도 의미가 있었지만 실 제로는 고용보험사업의 목표와 실행 및 효과를 체계적, 비판적으로 분석하는 활동으로서 의의가 있었다[15]. 이런 의미에서 향후 이루어질 산재예방사업에 대한 평 가도 개별 사업의 성과에 대한 객관적이고 과학적인 평가, 평가결과의 환류 등을 통한 제도개선, 산재예방 사업 전체의 발전방향을 제시하는 것으로 추진될 필요 가 있으며 평가 결과를 통하여 평가관련 정보를 신속 히 제공, 확산하고 실질적인 정책개선조치를 추진할 필 요가 있다. 따라서 향후 본 연구에서 개발된 가중치를 반영한 평가로 산재예방사업의 발전방향을 제시하는 연구가 후속 진행되어야 하겠다.

\section{References}

[1] Winslow, C.E.A. The Untilled Fields of Public Health. Science, n.s. p. 23, 1920.01

[2] U.S. Department of Health and Human Services, Centers for Disease Control and Prevention. Office of the Director, Office of Strategy and Innovation. Introduction to program evaluation for public health programs: A self-study guide Atlanta, GA: Centers for Disease Control and Prevention, 2005.11

[3] GAO, Evaluations Help Measure or Explain Performance. United States General Accounting
Office. 2000.02

[4] Rossi, P.H., Freeman, H.E., \& Lipsey, M.W. Evaluation: A systematic approach. Edition 6. Thousand Oaks, CA: Sage Publications, Inc 1999.02

[5] Chen, H. Practical Program Evaluation: Assessing and Improving Planning, Implementation, and Effectiveness. Thousand Oaks: Sage Publications, Inc 2005.12

[6] EU, European Commission Evaluation of $\mathrm{EU}$ activities 2005.06

[7] Yarbrough, D. B., Shulha, L. M., Hopson, R. K., and Caruthers, F. A. The program evaluation standards: A guide for evaluators and evaluation users (3rd ed.). Thousand Oaks, CA: Sage, 2011.03

[8] GAO. Program Evaluation. Experienced agencies follow a similar model for priority research United States General Accounting Office. 2011.04

[9] Scriven, Micahel. Beyond formative and summative evaluation. In Gredler, M. E. Program Evaluation. (p. 16) New Jersey: Prentice Hall, 1991.07

[10] Executive Board of the United Nations Development Programme and of the Unitied Nations Population Fund. The evaluation policy of UNDP - Item 4 of the provisional agenda Evaluation. NY. 2011.02

[11] Chen, H.T. Practical program evaluation. Assessing and improving planning, implementation and effectiveness. Thousand Oaks, Sage Publications, 2005.02

[12] 권민영, 구본재, 이국희. $\mathrm{AHP}$ 기법을 적용한 IT프 로젝트 사전타당성 평가항목의 가중치 산출. Information Systems Review, 한국경영정보학회 지, 8(1), 265-285, 2006.04

[13] 송성환, 권성훈, 박진범 외. Delphi를 사용한 $\mathrm{AHP}$ 방법론에 관한 연구. 대한산업공학회지 26(1): 53 $\sim 64,2008.10$

[14] The Analytic Hierarchy Process (AHP), Thomas Saaty, 1980.05

[15] 한국직업능력 개발원, 고용보험 사업심층 평가, 2010.02 
저 자 소 개

이 준 희

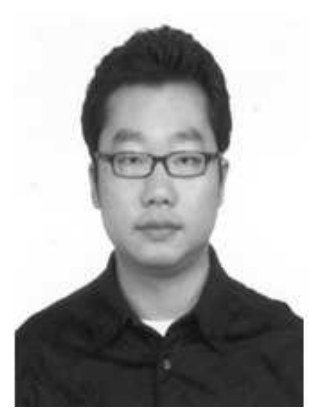

주소: 서울시 서대문구 신촌동 450 연세의료원

\section{정 필 균}

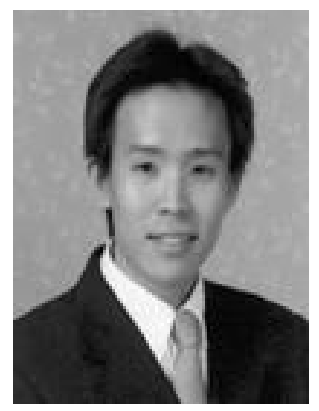

주소: 서울시 서대문구 신촌동 450 연세의료원

\section{이 정 배}

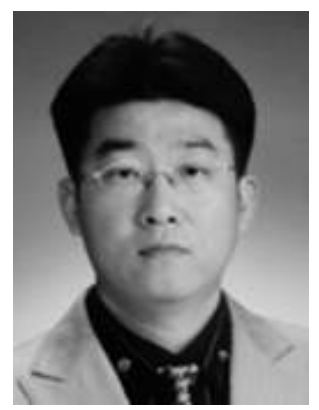

포천중문의과대학 졸업

연세대학교 대학원 보건학 박사수료 단국대학교 의과대학 임상조교수 관심분야: 직업환경의학
노 재 훈

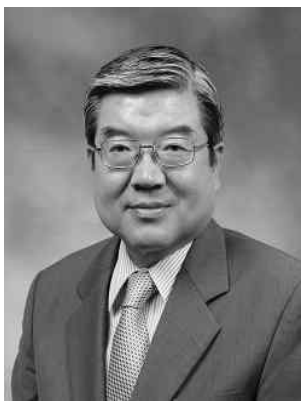

연세대학교 의과대학 졸업

연세대학교 대학원 보건학 박사

연세대학교 의과대학 예방의학교 실 교수, 연세대학교 의과대학 예 방의학교실 주임교수, 연세대학교 세브란스병원 산업보건센터 소장 인천 근로자 건강센터 소장 관심분야: 직업환경의학, 예방의학 주소: 서울시 서대문구 신촌동 450 연세의료원

원 종 욱

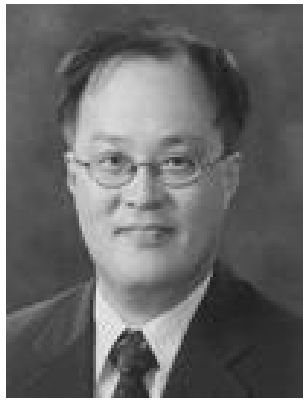

연세대학교 의과대학 졸업 연세대학교 대학원 보건학 박사 연세대학교 의과대학 예방의학교 실 교수

연세대학교 세브란스병원 산업보 건센터 부소장

인천 근로자 건강센터 부소장 관심분야: 직업환경의학, 예방의학 주소: 서울시 서대문구 신촌동 450 연세의료원

주소: 충남 천안시 동남구 망향로 201 단국대학교병원 